\title{
Modeling Extreme Climate Events: Two Case Studies in Mexico
}

\author{
O. Rafael García-Cueto and Néstor Santillán-Soto \\ Universidad Autónoma de Baja California \\ Instituto de Ingeniería \\ México
}

\section{Introduction}

The most severe impacts of climate on human society and infrastructure as well as on ecosystems and wildlife arise from the occurrence of extreme weather events such as heat waves, cold spells, floods, droughts and storms. Recent years have seen a number of weather events cause large losses of life as well as a tremendous increase in economic losses. According to the IPCC (2007), an extreme weather event is an event that is rare at a particular place and time of year. Definitions of rare vary, but an extreme weather event would normally be as rare as or rarer than the $10^{\text {th }}$ or $90^{\text {th }}$ percentile of the observed probability density function. Changes in frequency or/and intensity of extreme events can affect not only human health, directly through heat and cold waves and indirectly by floods or pollution episodes, but also for example, on crops or even insurance calculations. Climate extremes associated with temperature (heatwaves) and precipitation (heavy rain, snow events, droughts) can also affect energy consumption, human comfort and tourism and are responsible for a disproportionately large part of climate-related damages (Easterling et al., 2000; Meehl et al., 2000). Extreme weather events recorded in recent years, and associated losses of both, lives and economics goods, has captured the interest of the general public, governments, stakeholders and media. The scientific community has responded to this inquiry and has raised interest in studying with more attention to detail. Our understanding of the mean behavior of climate and its normal variability has been improving significantly during the last decades. In comparison, climatic extreme events have been hard to study and even harder to predict because they are, by definition, rare and obey different statistical laws than averages. In particular, extreme value analysis usually requires estimation of the probability of events that are more extreme than any that have already been observed, and they are linked to small probabilities. Climate extremes can be placed into two broad groups: (i) those based on simple climate statistics, which include extremes such as a very low or very high daily temperature, or heavy daily or monthly rainfall amounts, that occur every year; and (ii) more complex event-driven extremes, examples of which include drought, floods, or hurricanes, which do not necessarily occur every year at a given location. Katz \& Brown (1992) first suggested that the sensitivity of extremes to changes in mean climate may be greater than one would assume from simply shifting the location of the climatological distributions. Since then, observations of historical changes as well as future 
projections confirm that changes in the distributional tails of climate variables may not occur in proportion to changes in the mean, particularly for precipitation, and may not be symmetric in nature, as demonstrated by differential changes in maximum vs. minimum temperatures (e.g., Kharin \& Zwiers, 2005; Deguenon \& Barbulescu, 2011).

With respect to changes in climatic extremes, the Fourth Assessment Report of IPCC (2007) noted that since 1950 the number of heatwaves has increased and widespread increases have occurred in the numbers of warm nights. The extent of regions affected by droughts has also increased as precipitation over land has marginally decreased while evaporation has increased due to warmer conditions. Generally, numbers of heavy daily precipitation events that lead to flooding have increased, but not everywhere. Tropical storm and hurricane frequencies vary considerably from year to year, but evidence suggests substantial increases in intensity and duration since the 1970s. In the mid-latitudes, variations in tracks and intensity of storms reflect variations in major features of the atmospheric circulation, such as the North Atlantic Oscillation.

As extreme events are, by definition, rare and unusual, the statistical quantification of potential change in their trends and intensity becomes a very difficult task (Palmer \& Räisänen, 2002). So this chapter begins with a background section covering the origins of the statistics of extremes and applications of this statistics toward weather extremes. An overview of the statistical theory of extreme values with emphasis on block maxima approach and peaks over threshold is then provided, followed by two case studies in two cities of Mexico: a climatic application of modeling summer maximum temperatures in an arid city, and modeling of daily rainfall over a threshold in a humid city.

For contrasting the results obtained with extreme value theory, scenarios of summer maximum temperature and daily rainfall, with climate forcing caused by anthropogenic effect, were projected. With this aim, we used a statistical-dynamic model with two emission scenarios, A2 and B2.

\section{Historical origins of statistics of extremes}

The astronomers were the first to be interested in establishing a criterion for the acceptance or rejection of an outlying value. One of the first researchers that studied statistics of extremes was Nicolaus Bernoulli, in 1709; he answered the question: if $n$ men of equal age die within $t$ years, what is the mean duration of life of the last survivor? In 1852, Benjamin Peirce published the first significance test for eliminating outliers from data sets. He determined the expected value of the largest of any given number of independent life-times, uniformly distributed on an interval (Gumbel, 1958). In 1922, Ladislaus von Bortkiewicz was the first to study extreme values that dealt with the distribution of range in random samples from a normal distribution. The importance of the work of Bortkiewicz is because he introduced the concept of distribution of largest value for the first time.

The first significant contribution to the field of Extreme Value Theory (EVT) was made by Fisher \& Tippett (1928) who attempted to find the distribution of the maximum, or minimum of the data. The Fisher-Tippett Theorem states that, if the distribution of the normalized maximum of a sequence of random variables converges, it always converges to the Generalized Extreme Value (GEV) distribution, regardless of the underlying 
distribution; this result is very similar to the central limit theorem. Maurice Fréchet in the year 1927, was the first in obtain an asymptotic distribution of the largest value. He introduced the stability postulate according to which the distribution of the largest value should be equal to the initial one, except for a linear transformation. The problem of finding the limiting distribution of the maximum of a series of random variables was also later solved by B. Gnedenko (1943), who continued Fisher's research, and gave necessary and sufficient conditions under which three asymptotic distribution are valid. Emil J. Gumbel developed new distributions in the 1950s; his book Statistics of Extremes (Gumbel, 1958) was important contribution to EVT above all in the field of engineering. In 1970, L. de Hann provided a rigorous mathematical framework about theory of regular variation, which has played a crucial role in EVT. Pickands (1975) generalized them classic limit laws proposing model exceedances above a large threshold, and data above that threshold were fit to the Generalized Pareto Distribution (GPD). The Generalized Extreme Value distribution and the Generalized Pareto Distribution are just the tip of the iceberg of an entire new and quickly growing branch of statistics. The first application was to answer environmental questions, quickly followed by the finance industry. In 1990's multivariate and other techniques explored as a means to improve inference, and 2000's interest in spatial and spatio-temporal applications, and in finance. Textbooks on EVT include to Leadbetter et al., (1983) treat the general theory of extreme values of mainly one-dimensional stochastic sequences and processes; Embrechts et al. (1997) combine theoretical treatments of maxima and sums with statistical issues, focusing on applications from insurance and finance; Kotz \& Nadarajah (2000) give a comprehensive and down-to-earth survey of the theory and practice of extreme value distributions; Coles (2001) has more emphasis on applications; Beirlant et al. (2004) covers a wide range of models and application areas, including risk and insurance, and contains also material on multivariate and Bayesian modeling of extremes; Finkenstädt \& Rootzén (2004) explore the application and theory of extreme value in finance, insurance, environment and telecommunications; De Haan \& Ferreira (2006) focuses on theoretical results along with many applications; and Reiss \& Thomas (2007) is a book with an introduction to parametric model, exploratory analysis and statistical inference for extreme values.

\section{Extreme Value Theory}

Most statisticians aim to characterize typical behavior and focus on the center of data. EVT aims to characterize rare events by describing the tails of the underlying distribution. Probabilistic EVT deals with the asymptotic stochastic behavior of extreme order statistics of a random sample, such as the maximum and the minimum of independent identically distributed (iid) random variables. EVT has been one of the most quickly developing areas in the last decades (Hadživuković \& Emilija, 2005). It has found many applications (Berning, 2010) in different areas such as: Environmental (Floods, wave heights, wind speeds, heat waves, cold spells, pollutant concentrations), Engineering and Reliability (material strength, metal fatigue, corrosion), Finance (portfolio risk, value-at-risk, insurance risk, financial econometrics), Sociology ((human longevity, flood risk, management strategies, sport records), Statistical Methodology (multiple testing, simultaneous inference), telecommunications and biostatistics. 
The historical cornerstone of EVT is the Generalized Extreme Value (GEV) distribution which classically models block maxima data (or minima) over certain slices of time (such as annual maximum precipitation, monthly maximum/minimum temperature). According to EVT, identically distributed block maxima can be modeled with a GEV distribution defined by equation (1), in which $G$ is the Cumulative Distribution Function (CDF) of block maximum $\mathrm{z}$.

$$
G(z ; \mu, \sigma, \xi)=\exp \left[-\{1+\xi(\mathrm{z}-\mu) / \sigma\}_{+}^{-1 / \xi}\right]
$$

where $x_{+}=\max (x, 0)$. The parameter $\mu$ represents the location parameter $(-\infty<\mu<\infty)$, determining the location of the peak of $f ; \sigma$ the scale parameter $(\sigma>0)$, determining the "wideness" of the distribution, and $\xi$ the all-important shape parameter $(-\infty<\xi<\infty)$ which determines the nature of tail behavior of the maximum distribution. The justification for the GEV distribution arises from an asymptotic argument. As the sample size increases, the distribution of the sample maximum, say $X$, will asymptotically follow either Fréchet $(\xi>0)$, Weibull $(\xi<0)$, or Gumbel $(\xi=0)$ distribution (Naveau et al., 2005). Each of the three types of distributions has distinct forms of behavior in the tails. The Weibull is bounded above, meaning that there is a finite value which the maximum cannot exceed. The Gumbel distribution yields light tail, meaning that although the maximum can take on infinitely high values, the probability of obtaining such levels become small exponentially. The Fréchet distribution with a heavy tail, decays polinomially, so that higher values of the maximum are obtained with greater probability, that would be the case with a lighter tail (Gilleland \& Katz, 2006). The flexibility of the GEV to describe all three types of tail behavior makes it a universal tool for modeling block maxima. As Naveau et al. (2005) say..."it is important to stress that the GEV is the proper fit to maxima not only from a parent distribution like the Gaussian one, but also from any continuous distribution (e.g., exponential, Cauchy, etc.). Hence the methodology is general and independent of specific numerical values"...

\subsection{The three types of extreme value distributions}

There are three extreme value distributions - one for ordinary parent distributions (the Gumbel type), another for many parent distributions that are truncated on the right (the Weibull type) and a last for parent distributions that lack all or higher moments (the Fréchet type). The Gumbel type includes most ordinary distributions - for example, the normal, lognormal, gamma, exponential, Weibull and logistic - and was the focus of classical EVT. The Gumbel extreme value distribution is often referred to as the extreme value distribution. Collectively, these three classes of distribution are termed the extreme value distribution, with types I, II and III widely known as the Gumbel, Fréchet and Weibull families respectively. Each family has a location and scale parameter, $\mu$ and $\sigma$, respectively; additionally, the Fréchet and Weibull families have a shape parameter $\xi$.

Type I: Gumbel-type distribution

$$
\operatorname{Pr}[\mathrm{X} \leq \mathrm{x}]=\exp \left[-\mathrm{e}^{(\mathrm{x}-\mu) / \sigma}\right]
$$


Type II: Fréchet-type distribution

$$
\operatorname{Pr}[X \leq x]=\left\{\begin{array}{r}
0, x<\mu \\
\exp \left\{-\left(\frac{x-\mu}{\sigma}\right)^{-\varepsilon}\right\}, x \geq \mu
\end{array}\right.
$$

Type III: Weibull-type distribution

$$
\operatorname{Pr}[\mathrm{X} \leq \mathrm{x}]=\left\{\begin{array}{r}
\exp \left\{-\left(\frac{\mu-\mathrm{x}}{\sigma}\right)^{\varepsilon}\right\}, \\
0, \mathrm{x} \leq \mu \\
0, \mathrm{x}>\mu
\end{array}\right.
$$

\section{Threshold models}

One statistical method for analyzing extreme values is to fit data to an extreme-value distribution. This method is carried out by two alternative approaches: block maxima and peaks over threshold (POT). The approach leading to distribution (1) assumes data are maxima from finite-sized blocks, such as annual maximum temperature. However, if daily observations are available, models which use only each year's annual maximum discards other extreme data that could provide additional information. The POT approach allows for more data to inform the analysis. The POT models are generally considered to be the most useful applications due to their more efficient use of the data on extreme values. For the POT approach, a threshold is first determined, and data above that threshold are fit to the Generalized Pareto Distribution (GPD), which is based on the excesses above a threshold, and it also has an asymptotic justification, such as EVT. The amounts by which observations exceed a threshold $u$ (called exceedances) should approximately follow a GPD as $u$ gets large and sample size increases. In this case, the tail of the distribution is characterized by the equation 5.

$$
\mathrm{G}(\mathrm{x} ; \widetilde{\sigma}, \xi, \mathrm{u})=1-[1+\xi(\mathrm{x}-\mathrm{u}) / \widetilde{\sigma}]^{-1 / \xi}
$$

where $x-u>0,1+\xi(x-u) / \tilde{\sigma}>0$ and $\widetilde{\sigma}=\sigma+\xi(u-\mu)$. The parameter $\mu$ represents the location parameter, and $\widetilde{\sigma}$ the scale parameter. This function gives the cumulative probability for $\mathrm{X}$ exceeding the value of $\mathrm{x}$, given that it already exceeds the threshold $u$. The duality between the GEV and generalized Pareto families means that the shape parameter $\xi$ is dominant in determining the qualitative behavior of the GPD, just as it is for the GEV distribution. In particular, the values of $\xi$ are common across the two models. Furthermore, the value of $\widetilde{\sigma}$ is found to be threshold-dependent, except in the case where the limit model has $\xi=0$.

Threshold selection is critical to any POT analysis. Too high a threshold could discard too much data leading to high variance of the estimate, but too low a threshold is likely to violate the asymptotic basis of the model, leading to bias. The standard practice is to adopt as low a threshold as possible, subject to the limit model providing a reasonable approximation. So, threshold selection is a commitment between choosing a high enough value for the asymptotic theorem can be considered accurate, and low enough to have the sufficient material to estimate the parameters $\xi$ and $\beta$. 
Other important assumption for the GPD is that the threshold exceedances are independent. Such an assumption is often unreasonable for weather and climate data because high values of meteorological and climatological quantities are often succeeded by high quantities (e.g. high rain day is likely to be followed by another high rain day). An approach frequently employed to handle such dependency is to decluster the data by identifying clusters and to utilize only a summary of each cluster; one of the simplest and most widely used methods for determining clusters is runs de-clustering (Gilleland \& Katz, 2006).

\section{Return levels (quantiles)}

When considering extreme values of a random variable, one is interested in the return level of an extreme event, defined as the value $z_{\mathrm{p}}$, such that there is a probability of $p$ that $z_{\mathrm{p}}$ is exceeded in any given year, or alternatively, the level that is expected to be exceeded on average once every $1 / p$ years $(1 / p$ is often referred to as the return period); in extreme value terminology, $z_{p}$ is the return level associated with the return period $1 / p$. For example, if the 100 -year return level for temperature is found to be $45^{\circ} \mathrm{C}$, then the probability of temperature exceeding (return period) $45^{\circ} \mathrm{C}$ in any given year is $1 / 100=0.01$. In particular, a 20-year return value is the level that an annual extreme exceeds with probability $p=5 \%$. The quantity $1 / \mathrm{p}$ indicates the "rarity" of an extreme event and is usually referred to as the return period, or the waiting time for an extreme event.

The return level is derived from the distribution GEV or GPD by setting the cumulative distribution function equal to the desired probability/quantile, $1-p$, and then solving for the return level. Estimates of extreme quantiles of the annual maximum distribution can be obtained by the equation 6 .

$$
f(x)=\left\{\begin{array}{l}
\mu-\frac{\sigma}{\varepsilon}\left[1-y_{p}^{-\varepsilon}\right], \text { for } \varepsilon \neq 0 \\
\mu-\sigma \log y_{p}, \text { for } \varepsilon \neq 0
\end{array}\right.
$$

In the previous equation $y_{p}=-\log (1-p)$. If $z_{p}$ is plotted against $\log y_{p}$, the plot is linear in the case $\xi=0$. If $\xi<0$ the plot is convex with asymptotic limit as $\mathrm{p} \rightarrow 0$ at $\mu-\sigma / \xi$; if $\xi>0$ the plot is concave and has no finite bound. This graph is a return level plot. Because of the simplicity of interpretation, and because the choice of scale compresses the tail of the distribution so that the effect of extrapolation is highlighted, return level plots are particularly convenient for both model presentation and validation.

\section{Weather and climate extremes and its relationship with climate change}

There is general agreement that changes in the frequency or intensity of extreme weather and climate events is increasing in many regions in response to global climate change and would have profound impacts on both human society and the natural environment. This has motivated many studies of extremes in the climate in the first decade of 2000's (Meehl et al., 2000; Easterling et al., 2000; Rusticucci \& Barrucand, 2004; Kharin et al., 2007); Recent years have seen a number of weather and climate events cause large losses of life as well as a tremendous increase in economic losses from weather hazards. Examples of weather extremes in past decade (2001-2010) are showed in table 1 (WMO, 2011). 


\begin{tabular}{|c|c|}
\hline Year & Extreme weather events \\
\hline 2001 & $\begin{array}{l}\text { Extreme cold winter in Siberia and Mongolia. Minimum temperatures of near - } \\
60^{\circ} \mathrm{C} \text { across central and southern Siberia resulting in hundreds of deaths. Canada } \\
\text { recorded the eighteenth straight warmer-than-average season. }\end{array}$ \\
\hline 2002 & $\begin{array}{l}\text { Exceptionally heavy rains in central Europe caused flooding of historic } \\
\text { proportions, killing more than } 100 \text { people and forcing the evacuation of more } \\
\text { than } 450000 \text { people. Damage was estimated at US } 9 \text { billion in Germany alone. }\end{array}$ \\
\hline 2003 & $\begin{array}{l}\text { Europe recorded in August } 2003 \text { its worst heatwave. In many locations, } \\
\text { temperatures rose above } 40^{\circ} \mathrm{C} \text {. In Belgium, France, Germany, Italy, the } \\
\text { Netherlands, Portugal, Spain, Switzerland and the United Kingdom, } 40000 \text { to } 70 \\
000 \text { deaths were attributed to the heatwaves. }\end{array}$ \\
\hline 2004 & $\begin{array}{l}\text { Widespread winter storms in the Mediterranean region. Extreme hot conditions } \\
\text { persisted in Japan during the summer, with record-breaking temperatures. A } \\
\text { record number of } 10 \text { tropical cyclones made landfall in Japan, including. The first } \\
\text { tropical cyclone since the start of satellite records made landfall on the southern } \\
\text { coast of Brazil. In Afghanistan, drought conditions continued this year. }\end{array}$ \\
\hline 2005 & $\begin{array}{l}\text { This year was ranked in the top two warmest years along with 1998. Most active } \\
\text { Atlantic hurricane season on record. In Central America and the Caribbean } \\
\text { region, the most damage occurred from Hurricanes Dennis, Emily, Stan, Wilma } \\
\text { and Beta. In the United States, Hurricane Katrina was the deadliest hurricane to } \\
\text { hit the country since 1928, killing over } 1300 \text { people. Australia officially recorded } \\
\text { its warmest year on record. }\end{array}$ \\
\hline 2006 & $\begin{array}{l}\text { Heavy rains ended prolonged drought in the Greater Horn of Africa, leading to } \\
\text { the worst flooding in October/November in } 50 \text { years. Disastrous tropical } \\
\text { cyclones hit some south east Asian nations, including Typhoon Durian which } \\
\text { killed nearly } 1200 \text { people in the Philippines. }\end{array}$ \\
\hline 2007 & $\begin{array}{l}\text { Mexico suffered the worst flooding in five decades in November, causing the } \\
\text { worst weather-related disaster in its history. Severe to exceptional drought } \\
\text { continued in the south-east United States, with the driest spring on record and } \\
\text { the second worst fire season after } 2006 \text {. }\end{array}$ \\
\hline 2008 & $\begin{array}{l}\text { China witnessed the worst severe winter weather in five decades in January, } \\
\text { with over } 78 \text { million people affected by the freezing temperatures and heavy } \\
\text { snow. Tropical Cyclone Nargis with maximum winds of } 215 \mathrm{~km} / \text { hour was the } \\
\text { most devastating cyclone to strike Asia since 1991, causing Myanmar's worst } \\
\text { natural disaster ever. }\end{array}$ \\
\hline 2009 & $\begin{array}{l}\text { Australia was affected by exceptional heatwaves This was associated with } \\
\text { disastrous bushfires that caused more than } 170 \text { fatalities. Victoria recorded its } \\
\text { highest temperature with } 48.8^{\circ} \mathrm{C} \text { at Hopetoun, the highest temperature ever } \\
\text { recorded so far south in the world. }\end{array}$ \\
\hline 2010 & $\begin{array}{l}\text { This year was ranked as the warmest year on record, along with } 1998 \text { and } 2005 . \\
\text { Hundreds of records for daily minimum temperatures were broken in the United } \\
\text { States. Heavy snowfall disrupted air and road traffic in Europe, the United States } \\
\text { and China. Australia faced its worst flooding in about } 50 \text { years. }\end{array}$ \\
\hline
\end{tabular}

Table 1. Some Weather Extremes in last decade (2001-2010), (WMO, 2011). 


\section{Weather and climate extremes: Review methods for their modeling}

Quantifying and predicting changes in mean climate conditions and shifts in the frequency of extreme events is a daunting task that is vigorously pursued by many scientists, federal agencies, and private companies. Basically there are two essential tools for studying extreme weather and climate events: a) modeling using General Circulation Models (GCMs), and b) statistical modeling using Extreme Value Theory (EVT). Climate Models are derived from fundamental physical laws, which are then subjected to physical approximations appropriate for the large-scale climate system, and then further approximated through mathematical discretization (IPCC, 2007). Models show significant and increasing skill in representing many important mean climate features, such as the large-scale distributions of atmospheric temperature, precipitation, radiation and wind, and of oceanic temperatures, currents and sea ice cover. Simulations with global coupled ocean-atmosphere general circulation models (CGCMs) forced with projected greenhouse gas and aerosol emissions are the primary tools for studying possible future changes in climate mean, variability, and extremes. The ability of the generation of atmospheric general circulation models to simulate temperature and precipitation extremes was documented by Kharin et al. (2005, 2007). However, because the simulation of extremes pushes the limits of what GCMs are capable of, it is important to consider a number of advantages when using GCMs to study weather and climate extremes (Yin \& Branstator, 2007). One advantage is the possibility of using a GCM to study extremes in climates different from that observed today, another important advantage is that GCM experiments can be designed to test hypotheses about the dynamics and other factors that influence extremes. A third advantage is that GCMs can be used to produce sample sizes of extremes much larger than found in the short observational record. Thus, while the observational record may be too short for robust statistics of extremes, a GCM dataset of hundreds or thousands of years of model time could produce robust extreme statistics. Accordingly by Tebaldi et al. (2006), GCMs are increasingly being used to study climate and weather extremes for societal and ecological impacts (Jentsch et al., 2007).

On the other hand, the complexity of the climate system always required the application of statistical methods to identify relationships among the climate quantities that were hidden in the multitude of spatial and temporal scales in play (Navarra, 1999). In the course of the years it has been shown that statistical techniques are a powerful tool that can lead to an understanding of nature as profound as other scientific devices. In particular, the use of EVT is a tool that seeks to provide an estimate of the tails of the original distribution using only extreme values of the data series. Many studies use EVT related to extreme weather and climate events and their impact: in ecology (Parmesan et al., 2000; Katz et al., 2002; Dixon et al., 2005); in disaster losses (Pielke, 2007; WMO, 2011); in heatwaves, extreme rainfall, snow events and droughts and related damages that affect to the community and stakeholders (Easterling et al., 2000; Meehl et al., 2000; Katz et al., 2005; Garcia-Cueto et al., 2010; Deguenon \& Barbulescu, 2011).

\section{Examples of application of EVT to extreme climate events in two cities of Mexico: Mexicali and Villahermosa}

This part of the chapter focuses on the analysis of daily maximum temperature records from a local weather station in the northwest of Mexico, and daily rainfall records from a local 
weather station in southwest of Mexico. The city of northwest Mexico is named Mexicali, and the city of southeast Mexico is named Villahermosa. First we describe the climate of each city, and then Extreme Value Theory is applied. In the case of Mexicali City the summer maximum temperature data was fitted to a Generalized Extreme Value (GEV) distribution by using a block maxima approach. Furthermore, from 5-year to 500-year return level and shape parameter confidence limits were found, respectively. In the case of Villahermosa City, daily precipitation data over a threshold were fitted to Generalized Pareto Distribution (GPD). As in the case of Mexicali City, rainfall maximum return levels of several time periods for Villahermosa City are estimated.

\subsection{Location and climate in Mexicali City}

Mexicali is located in the Sonoran desert of northwestern Mexico, at $32.55^{\circ} \mathrm{N}, 115.47^{\circ} \mathrm{W}$ and 4 meters above sea level; it borders Calexico, CA to the north and Sonora, Mexico to the west. Mexicali features a dry arid climate [Garcia's climate classification BW( $\left.\left.h^{\prime}\right)(\mathrm{hs})\left(\mathrm{x}^{\prime}\right)\right]$, with extremely hot summers and cold winters. Mexicali is one of the hottest cities of Mexico, with average July high temperatures of $42.2^{\circ} \mathrm{C}$. Average January highs are around $21{ }^{\circ} \mathrm{C}$. Mexicali receives $90 \%$ of the maximum potential hours of daylight each year. On average Mexicali receives about $75 \mathrm{~mm}$ of rain annually. On July 28, 1995, Mexicali reached its alltime high of $52{ }^{\circ} \mathrm{C}$.

\subsection{EVT applied to summer maximum temperature at Mexicali City}

Extreme Value Theory (EVT) was applied to find the probability of the highest summer temperatures, and quantify return levels, at Mexicali City. The analysis can be useful to help society prepare and protect itself from future dangerous temperatures. The data consists of the daily "summer" temperature records from a local weather station (Period 6/1/19519/15/2008, Station Mexicali 02033, Comision Nacional del Agua). Summer is defined in this research from 1 June to 15 September, the period for which maximum temperatures are very high. Data were fitted to a Generalized Extreme Value (GEV) distribution by using a block maxima approach. Furthermore, some predictions such as various return levels and shape parameter confidence limits were found. The Maximum Likelihood method for estimating the parameters (location, scale and shape) was used. The extremes package (Gilleland and Katz, 2006) of R (R Development Core Team, 2010) was used because it is an open source; it is particularly well oriented to climatic applications and has the ability to incorporate information about co-variables in order to estimate parameters. Figure 1 shows the plot of summer maximum temperature. It can be observed from figure 1 that the highest value is $52^{\circ} \mathrm{C}$ and lowest is $43.8^{\circ} \mathrm{C}$. Maximum-likelihood fitted parameter values are presented in Table 2.

The figure 2 shows diagnostic plots from the proposed fitting. Combining the estimates and standard errors, the approximate $95 \%$ confidence intervals are $(46.23,47.01)$ for $\mu,(1.112$, $1.645)$ for $\sigma$, and $(-0.005,-0.287)$ for $\xi$.

When the probability and quantile graphs were examined (fig. 2), and since the plotted data approximately are near-linear, it suggested that the underlying suppositions for the GEV distribution are reasonable for the summer maximum temperature data. According to the 
shape parameter $(\xi=-0.146)$, the most adequate distribution for modeling the summer maximum temperature occurrence is the Weibull distribution, which is bounded above, meaning that there are finite values which the maximum temperatures cannot exceed. Based on the results presented in Table 2, the estimate of upper limit is calculated as $\mu-\sigma / \xi=$ $46.623-1.379 /-0.146=56.012\left({ }^{\circ} \mathrm{C}\right)$. Testing the fit of the GEV probability density function to data was done using the chi-square goodness of fit test. The condition $\chi_{n}^{2} \leq \chi_{n, 0.05}^{2}$ is satisfied $(3.04<3.84)$.

The cumulative distribution function (CDF) of block maximum $\mathrm{z}$ is calculated from equation (1) as: $G(z, \mu, \sigma, \xi)=\exp \left\{-[1-0.14695((z-46.62329) / 1.3797)]^{\wedge}(1 / 0.14695)\right\}$. Figure 3 shows CDF for summer maximum temperature at Mexicali City.

\begin{tabular}{|l|c|c|}
\hline Parameter & Estimate & Standard Error \\
\hline Location $(\mu)$ & 46.623 & 0.198 \\
\hline Scale $(\sigma)$ & 1.379 & 0.136 \\
\hline Shape $(\xi)$ & -0.146 & 0.072 \\
\hline Negative log-likelihood & \multicolumn{2}{|c|}{104.98} \\
\hline
\end{tabular}

Table 2. GEV parameter estimates from fitting summer maximum temperatures at Mexicali, Mexico.

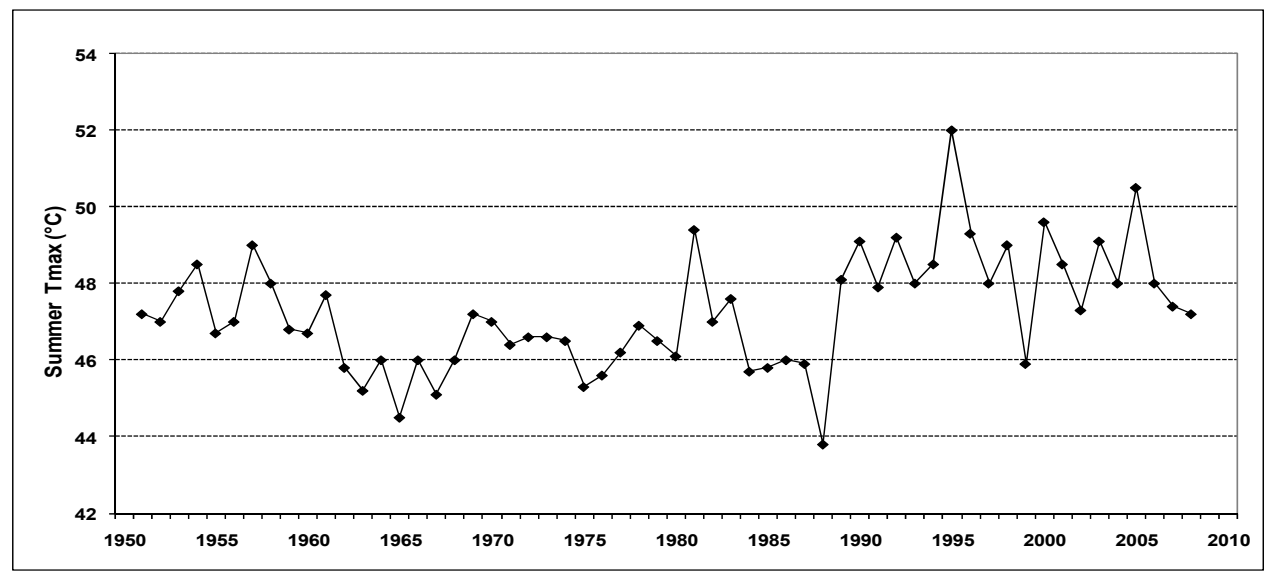

Fig. 1. Time plot of summer maximum temperature at Mexicali, Mexico (1951-2008). 


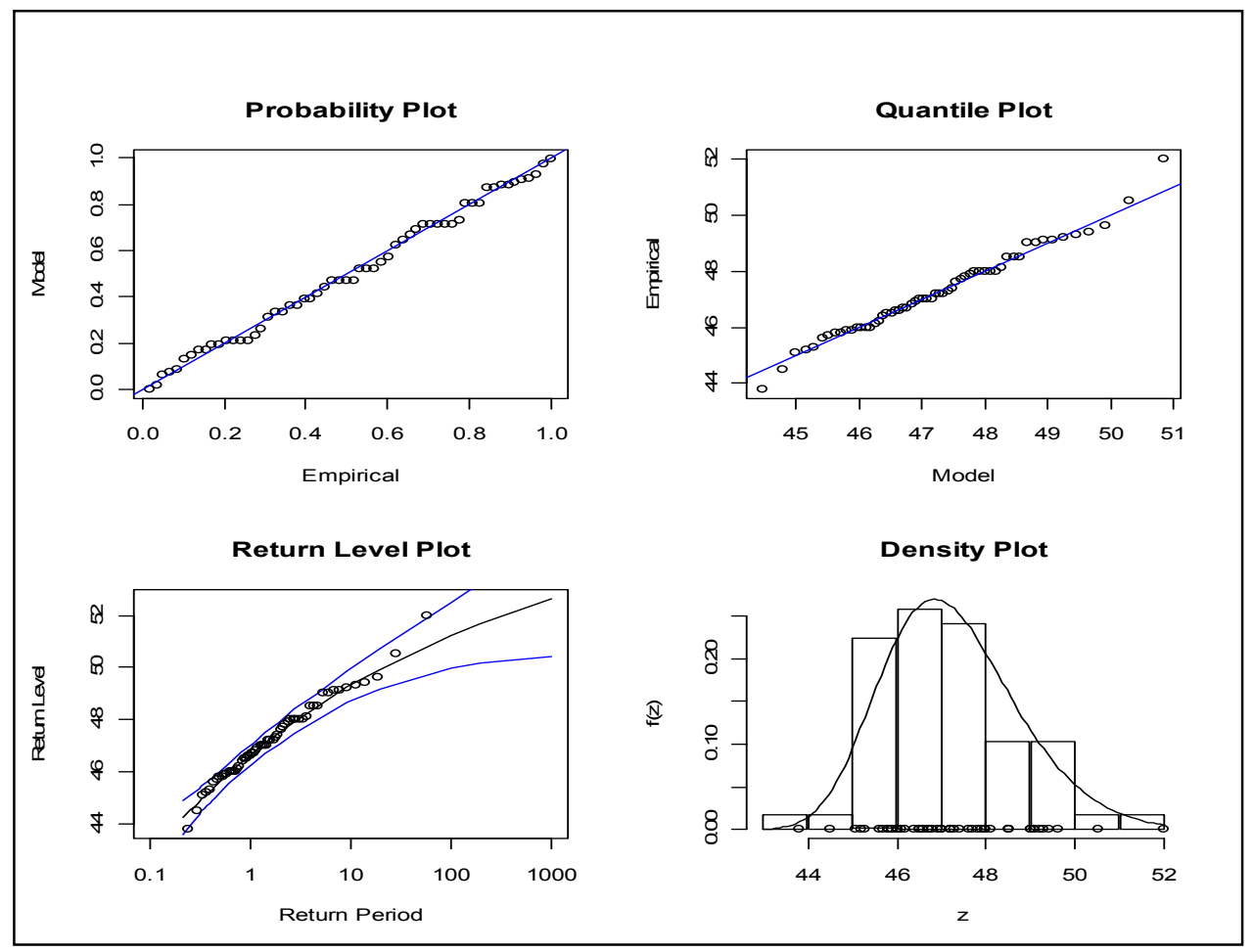

Fig. 2. GEV fit diagnostic plots for summer maximum temperature $\left({ }^{\circ} \mathrm{C}\right)$ at Mexicali, Mexico (1951-2008).

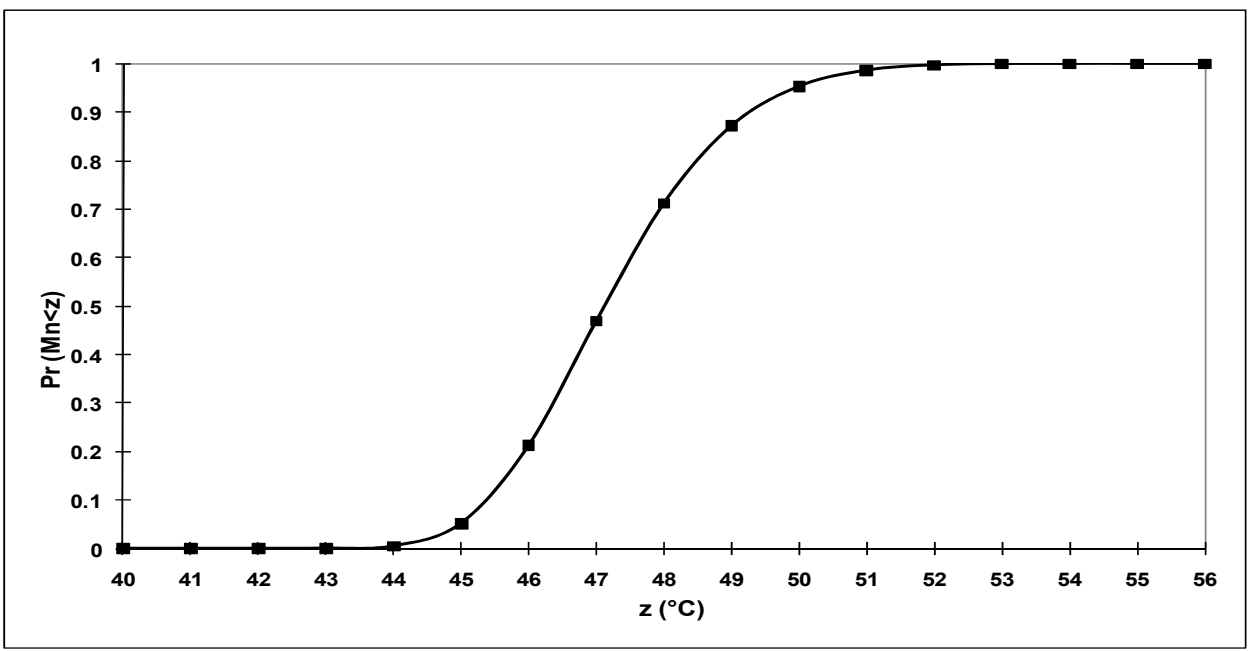

Fig. 3. GEV distribution fit to summer maximum temperature at Mexicali City, Mexico. 
With the CDF, we can calculate the return levels of the summer maximum temperature. This plot is shown in bottom left of figure 2 along the point-wise $95 \%$ confidence bounds estimated by the delta method. The delta method assumes that the parameters estimates are symmetric, which is not always the case for the shape parameter or extreme return level (Gilleland \& Katz, 2005). Greater accuracy of the confidence intervals can usually be achieved using the profile likelihood. Figure 4 show the profile log-likelihoods for the 100 -year return level. The estimated return level is $51.2^{\circ} \mathrm{C}$ with $95 \%$ confidence interval of $(50.4,53.1)$. Similarly, the $95 \%$ confidence interval of the shape parameter $\xi$ was $(-0.269$, 0.104). From the profile likelihood plots, the estimates were good because the dashed vertical lines intersected the likelihood at the same points as the lower horizontal line in both cases.

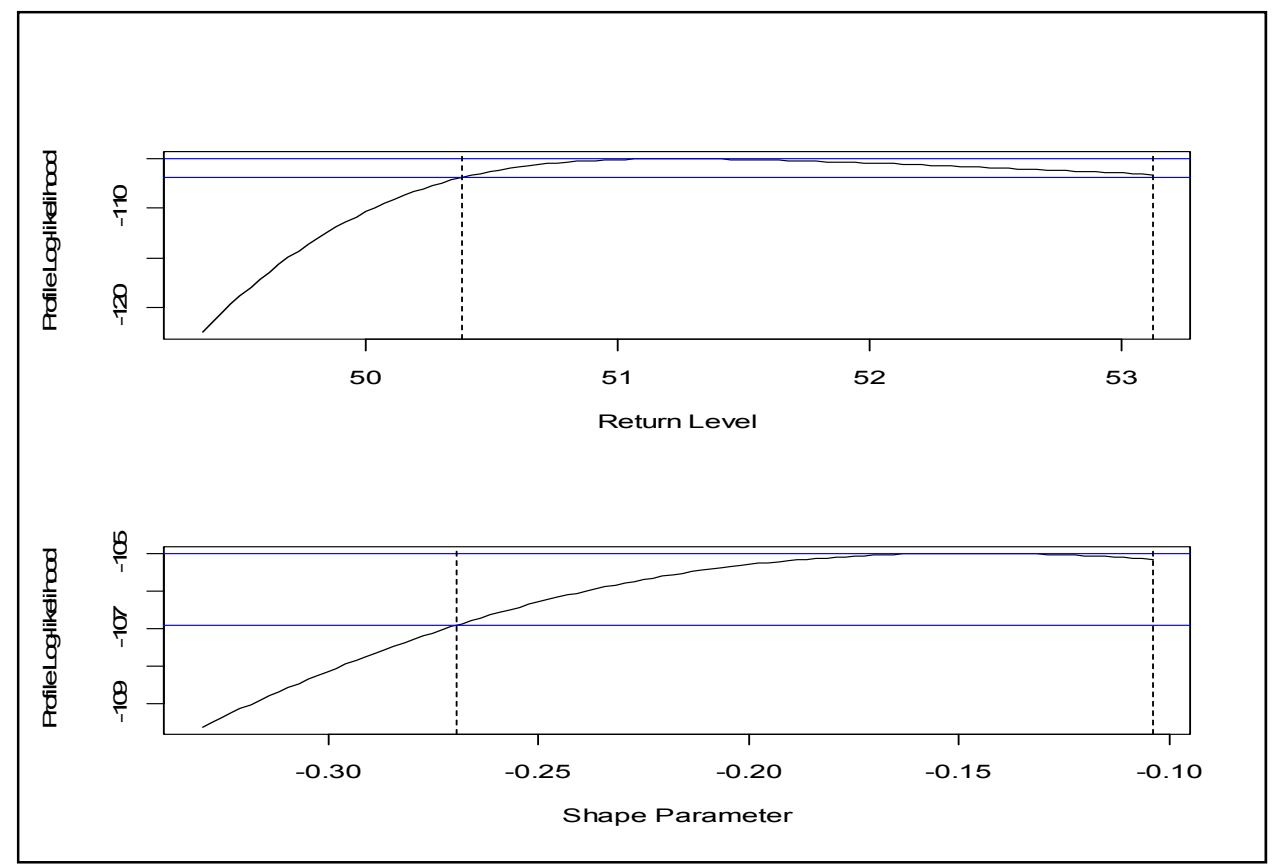

Fig. 4. 100-year profile likelihood plots for summer maximum temperature $\left({ }^{\circ} \mathrm{C}\right)$ at Mexicali Mexico in period from 1951 to 2008.

Table 3 shows the results of estimated return levels and 95\% confidence intervals.

It can be seen from Table 3 that the return levels for summer maximum temperature gradually increase for higher and higher return periods. Also the confidence intervals are increasingly wider as the return period is increasing. From the above results one would expect, per example, that summer maximum temperature $\left({ }^{\circ} \mathrm{C}\right)$ at Mexicali Mexico will exceed about $49.3^{\circ} \mathrm{C}$ on average every 10 years, and will exceed about 51.2 on average every 100 years, and will exceed about $52.2^{\circ} \mathrm{C}$ every 500 years. The $95 \%$ confidence intervals, in $\left({ }^{\circ} \mathrm{C}\right)$, were $48.7-50.0,50.4-53.1$, and 51.1-55.1, respectively. 


\begin{tabular}{|c|c|c|c|}
\hline Return period, yr & Return level $\left({ }^{\circ} \mathrm{C}\right)$ & Lower bound $\left({ }^{\circ} \mathrm{C}\right)$ & Upper bound $\left({ }^{\circ} \mathrm{C}\right)$ \\
\hline 5 & 48.5 & 48.0 & 49.0 \\
\hline 10 & 49.3 & 48.7 & 50.0 \\
\hline 15 & 49.7 & 49.1 & 50.6 \\
\hline 20 & 49.9 & 49.3 & 51.0 \\
\hline 25 & 50.1 & 49.5 & 51.4 \\
\hline 50 & 50.7 & 50.0 & 52.2 \\
\hline 75 & 51.0 & 50.2 & 52.8 \\
\hline 100 & 51.2 & 50.4 & 53.1 \\
\hline 500 & 52.2 & 51.1 & 55.1 \\
\hline
\end{tabular}

Table 3. Estimated return levels and 95\% confidence intervals for several period returns from having fit summer maximum temperature $\left({ }^{\circ} \mathrm{C}\right)$ at Mexicali, Mexico (summer) to the GEV distribution.

\subsection{Location and climate in Villahermosa Mexico}

Villahermosa, capital of the State of Tabasco, is located in southwest Mexico, at $17.98^{\circ} \mathrm{N}$, $92.91^{\circ} \mathrm{W}$ and 9 meters above sea level. Villahermosa features a tropical wet climate (Garcia's climate classification Am), with an annual average temperature of $26^{\circ} \mathrm{C}$ and an annual average precipitation of $1500 \mathrm{~mm}$. the City of Villahermosa is characterized by its warm and humid climate. Temperatures during spring and summer seasons reach upward of $40^{\circ} \mathrm{C}$, with humidity levels near around 30\% during the same period. During its short "winter", Villahermosa's climate is very humid, but daytime temperatures decrease to around $28^{\circ} \mathrm{C}$. In October 2007, Villahermosa suffered its worst flood in recorded history. Several hundred thousand people were displaced because of flooded homes.

\subsection{EVT applied to daily maximum rainfall at Villahermosa City}

Floods in Villahermosa City have recently become more destructive and projections show that this trend may become more pronounced. Part of this trend is linked to socio-economic factors, but a portion of the flood growth is linked to climate. As quantification of maximum rainfall is important for flood planning purposes, Generalized Pareto Distribution (GPD) by using Peaks Over Threshold (POT) was applied to the data base of daily rainfall records from a local weather station (period 10/1/1948-8/31/2010, Station 27054 Villahermosa, Comision Nacional del Agua of Mexico Country). Furthermore, predictions of several return levels and shape parameter confidence limits were determined. Also the maximum likelihood method for estimating the parameters of scale and shape was applied. Figure 5 shows the plot of daily rainfall in Villahermosa City.

In order to apply the POT, a threshold has to be fixed. The threshold has to be sufficiently large so that GPD is a suitable function for describing the tail of the cumulative distribution, and it has to be sufficiently small so that enough values are available to give an accurate estimation of the parameters of the GPD (Asensio, 2007). There is not any known, automatic procedure for the selection of the threshold. Here we choose a value of the threshold 
subjectively, and we verify the behavior of the parameters of the GPD for different values of the threshold. In our case, $u$ has been chosen as the value that exceeds $98.5 \%$ (21517) of the data points of the time series, leaving only $1.5 \%$ of the data points (336) as extreme values. For the dataset shown in figure 5 , we find $u=60 \mathrm{~mm}$. So 336 points above the threshold are used to fit the GPD, neglecting any time dependence. The maximum rainfall value recorded since the date is $340 \mathrm{~mm}$.

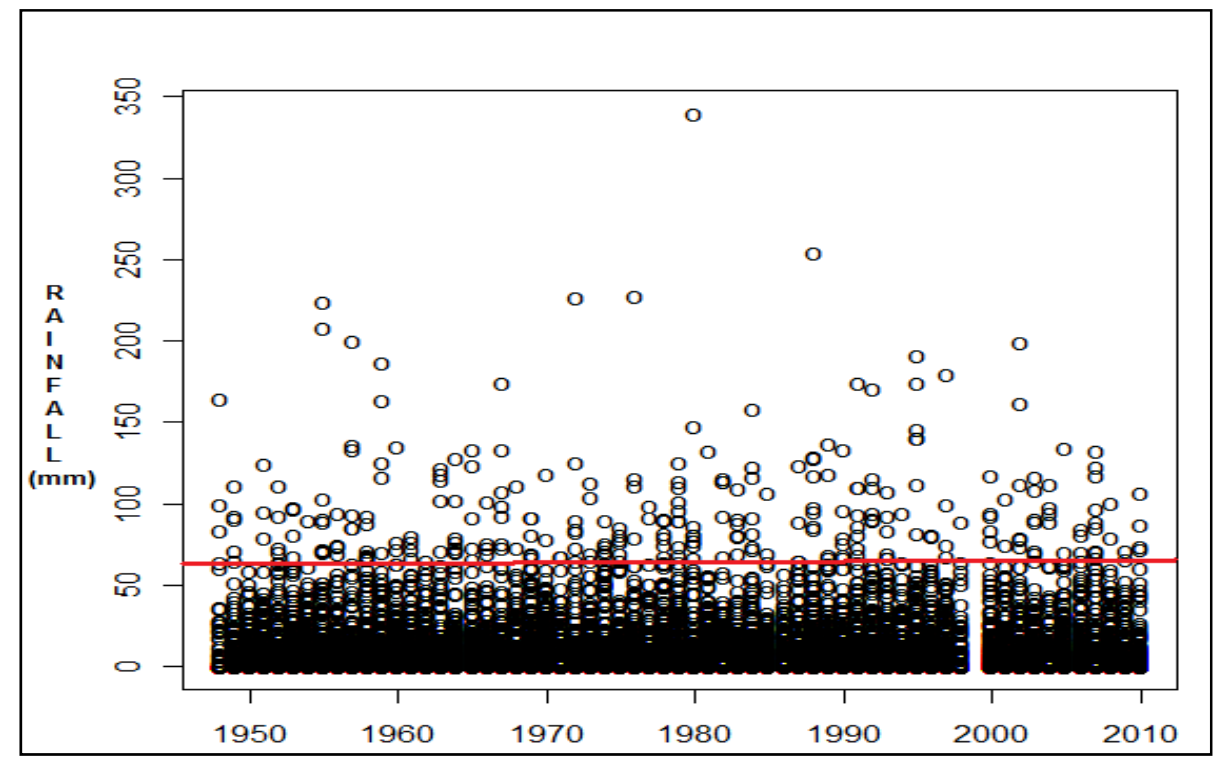

Fig. 5. Scatter plot of daily rainfall $(\mathrm{mm})$ at Villahermosa City. Horizontal line is the threshold of $60 \mathrm{~mm}$.

To show that the chosen threshold of $60 \mathrm{~mm}$ was adequate, the fit of the cumulative distribution with a range of thresholds was realized. The results are shown in figure 6 for different values of the threshold $u$, the upper panel showing the values obtained for $\sigma$ (modified scale) and the lower panel the values for $\xi$ (shape). If the GPD is a reasonable model for the exceedances above a certain threshold $\mathrm{u}_{0}$, the estimates $\sigma$ and $\xi$, should remain near-constant (Coles, 2001). It can be observed that selected threshold of $60 \mathrm{~mm}$ appears reasonable as the estimates of $\sigma$ and $\xi$ remain constant above level of $60 \mathrm{~mm}$. It is interesting note that for $u=80 \mathrm{~mm}$, approximately $0.8 \%$ of the data lie above the threshold, while for $u$ $=100 \mathrm{~mm}$, less than $0.4 \%$ of the data lie above. When there are less data available to estimate the parameters, it is obvious that the uncertainty increases.

The evaluation of significance of the model by likelihood ratio test was significant at the $5 \%$ confidence level. The empirical cumulative distribution function for points above the threshold is built and the values of $\sigma$ and $\xi$ that give the best fit were obtained. The parameters of the GPD were estimated by the maximum likelihood method using the statistical method for extreme values of $\mathrm{R}$ software; the values obtained are shown in table 4 . 


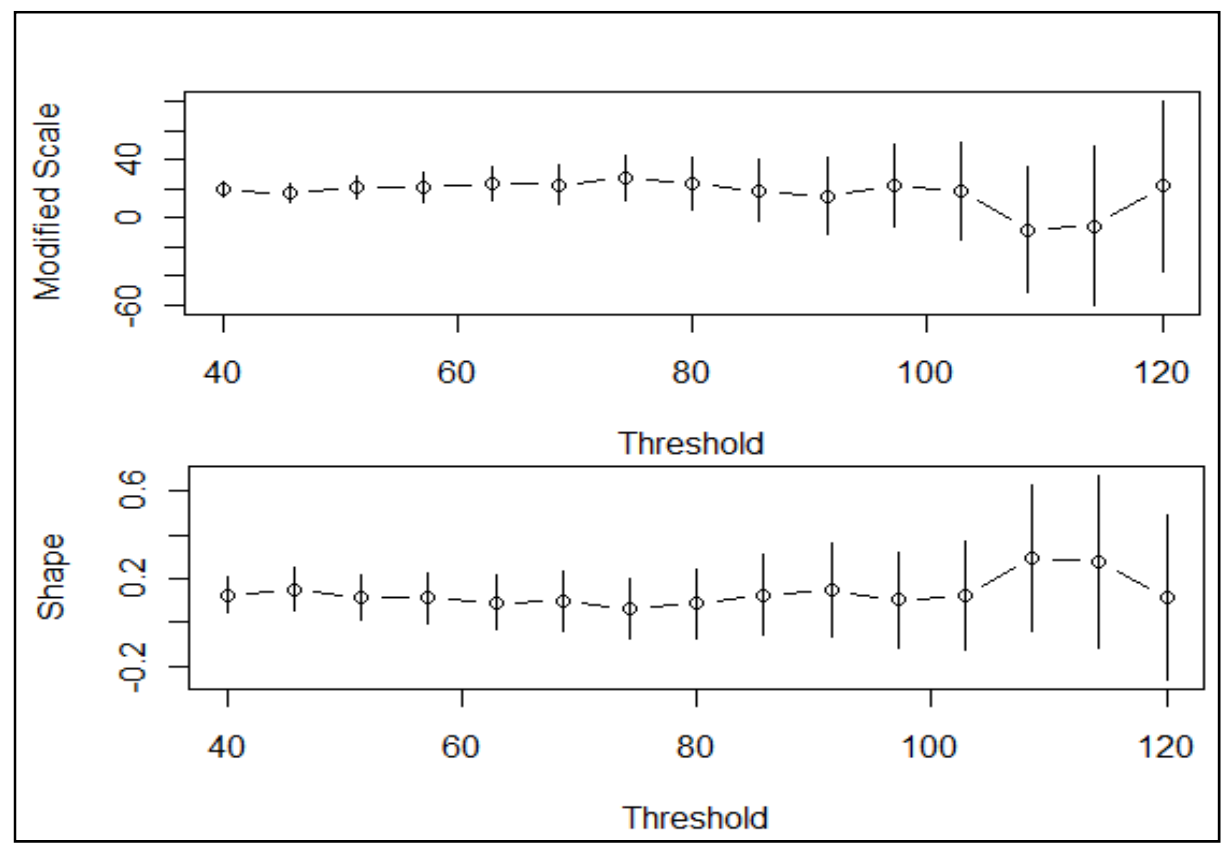

Fig. 6. Maximum likelihood estimates of $\sigma$ (Modified Scale) and $\xi$ (Shape) parameters obtained for different values of the threshold for the daily rainfall in Villahermosa during the period 1948-2010.

\begin{tabular}{|l|l|l|}
\hline Parameter & Estimate & Standard error \\
\hline Scale $(\sigma)$ & 27.15 & 2.27 \\
\hline Shape $(\xi)$ & 0.12 & 0.063 \\
\hline
\end{tabular}

Table 4. Parameters of GPD rainfall data at Villahermosa City. The values are obtained with a threshold of $60 \mathrm{~mm}$.

Figure 7 shows diagnostic plots from the proposed fitting, and suggest that probability and quantile graphs that the underlying assumption for the GPD are reasonably for these data. To assess the quality of fit between the GPD and this data set, the GPD density is superimposed on the histogram of the exceedances in figure 8 . The estimated shape parameter is clearly positive $(\xi=0.12$ with a standard error of 0.063$)$ and it indicates that the distribution is heavy tailed.

With these values, the cumulative distribution function is shown in the figure 9, where we show the value over the threshold on the horizontal axis and the value of the GPD on the vertical axis.

Since $\xi>0$, it is not useful to carry out a detailed inference of the upper limit, as was the case of summer maximum temperatures at Mexicali City. Instead, we focus on extreme return values. Return levels and shape parameter confidence limits (95\%) for rainfall over threshold of $60 \mathrm{~mm}$ were estimated (Table 5). 


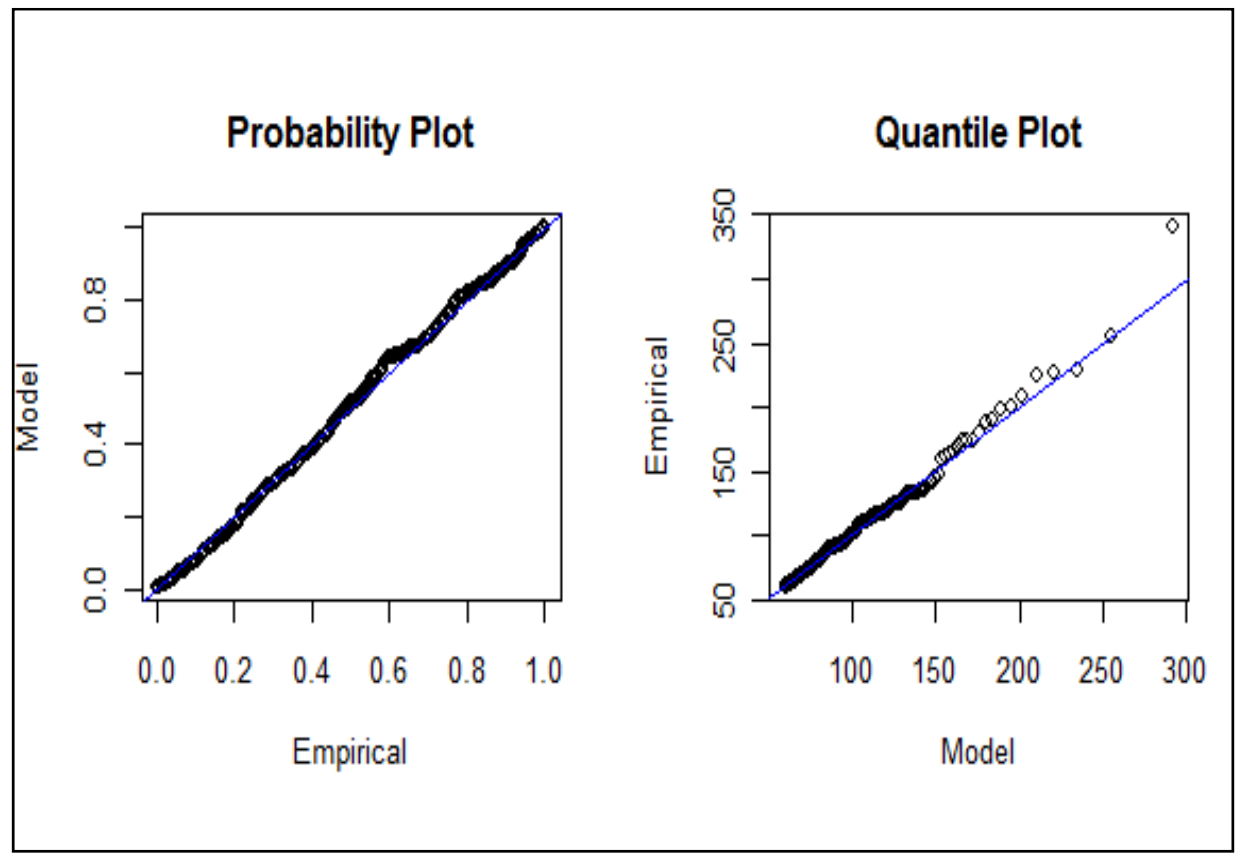

Fig. 7. Diagnostic plots for the threshold excess model fitted to daily rainfall data at Villahermosa, Mexico to a GPD.

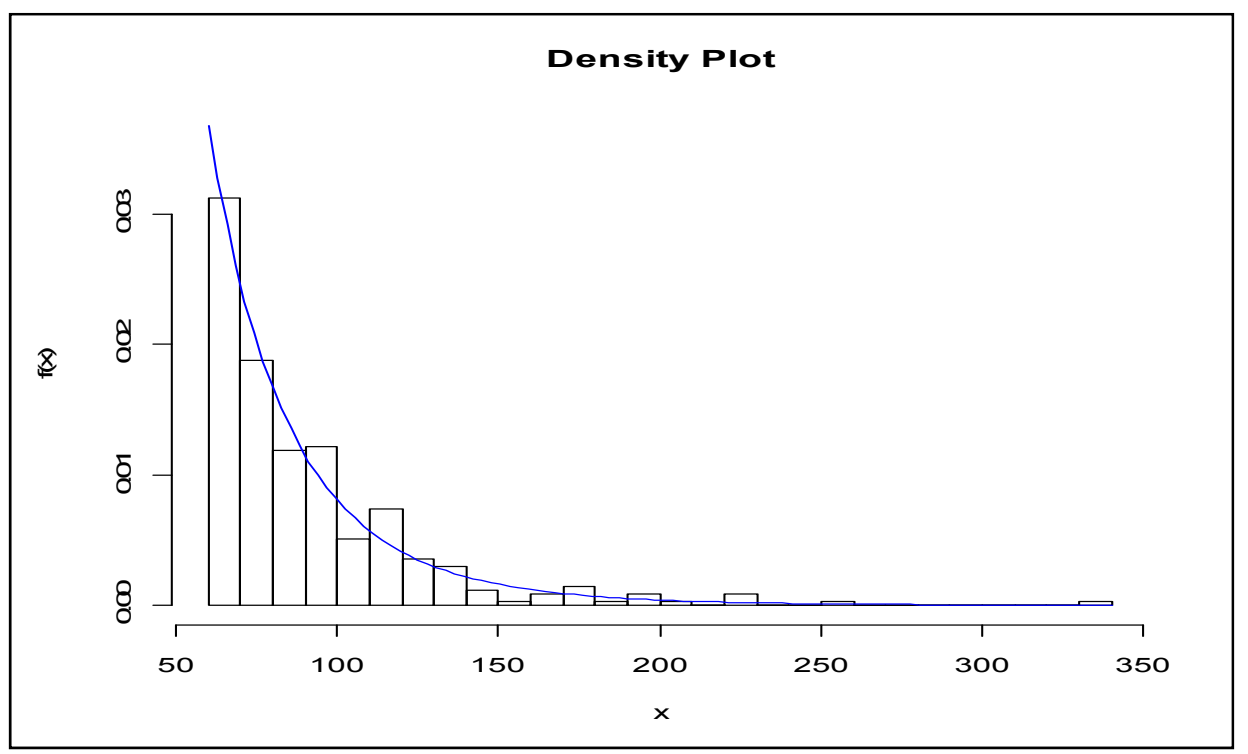

Fig. 8. Histogram and the fitted GPD density for the exceedances over threshold of $60 \mathrm{~mm}$ at Villahermosa, Mexico (1948-2010). 


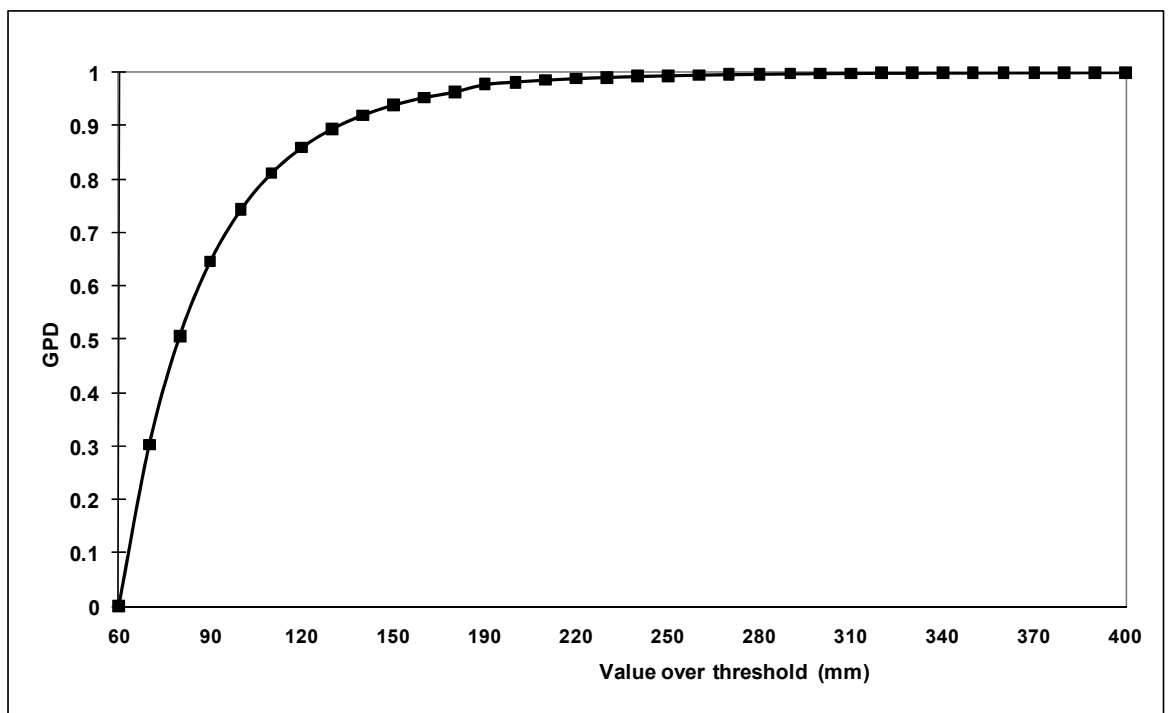

Fig. 9. GPD fit to rainfall over $60 \mathrm{~mm}$ at Villahermosa, Mexico (1948-2010).

\begin{tabular}{|l|l|l|l|}
\hline Return period, yr & Return level $(\mathrm{mm})$ & Lower bound $(\mathrm{mm})$ & Upper bound $(\mathrm{mm})$ \\
\hline 1 & 112.2 & 106.3 & 118.9 \\
\hline 5 & 172.1 & 157.0 & 195.5 \\
\hline 10 & 201.8 & 179.5 & 236.6 \\
\hline 20 & 234.1 & 202.2 & 277.0 \\
\hline 30 & 254.4 & 215.6 & 302.2 \\
\hline 50 & 281.4 & 232.5 & 335.9 \\
\hline 75 & 304.1 & 246.0 & 364.2 \\
\hline 100 & 320.9 & 256.7 & 385.1 \\
\hline 500 & 426.9 & 336.6 & 517.1 \\
\hline
\end{tabular}

Table 5. Estimated return levels and 95\% confidence intervals for several period returns from having fit rainfall daily data using a threshold of $60 \mathrm{~mm}$ at Villahermosa, Mexico to the GPD.

It can be seen from Table 5 that the return levels for rainfall over the threshold of $60 \mathrm{~mm}$ gradually increase for higher and higher return periods. Also the confidence intervals are increasingly wider as the return period increases. From the above results one would expect, per example, that rainfall over the threshold of $60 \mathrm{~mm}$ at Villahermosa Mexico will exceed about $201.8 \mathrm{~mm}$ on average every 10 years, and about $320.9 \mathrm{~mm}$ on average every 100 years, and about $426.9 \mathrm{~mm}$ every 500 years. The $95 \%$ confidence intervals $(\mathrm{mm})$ were 179.5-236.6, 256.7-385.1, and 336.6-517.1, respectively.

\section{Climate scenarios under climate forcing by anthropogenic effect}

In a world where the climate remains "stationary", and that inputs have a periodic behavior, the return periods of climatic variables would be a function only of its history recorded in 
the database, which, as we have seen, can be estimated with some uncertainty under the theory of extreme values; however, if we refer to a dynamic climate in which climate change caused by greenhouse gas forcing is driving current climate going to another different climate regime, the estimate of future values of atmospheric variables, must be addressed with other techniques. These estimations that are called climate scenarios are a plausible representation of future climate that have been constructed for explicit use in investigating the potential impacts of anthropogenic climate change. Climate scenarios often make use of climate projections that are descriptions of the modeled response of the climate system to scenarios of greenhouse gas and aerosol concentrations, by manipulating model outputs and combining them with observed climate data.

Climate scenarios in our case studies were generated using a statistical-dynamic model, the Statistical Downscaling Model SDSM (Wilby et al., 2002). SDSM model is a combination of a stochastic weather generator and a transfer function method that needs two types of daily data. The first type corresponds to local predictands of interest (in our case maximum temperature and rainfall), and the second type corresponds to the data of large-scale predictors of a grid box closest to the study area. For model calibration the source of these predictors is the National Center for Environmental Prediction (NCEP) re-analysis data set and for downscaling future climate scenarios is the model HadCM3 with two emission scenarios, A2 and B2.

Previous to the scenarios generation, the local atmospheric predictands and NCEP predictors for the period of 1961-1990 were split into two parts. The first part of 1961-1975 was used for model's calibration while the remaining data of 1976-1990 were used for model's validation, as an independent set of data, which revealed satisfactory results. Next the corresponding large scale predictors of HadCM3 were used to downscale the future climate data of the selected cities under the A2 and B2 emission scenarios. These emissions scenarios were allowed which compare the results, since they belong to different evolutionary lines. While the A2 scenario assumes a very heterogeneous world, whose underlying theme is self-reliance and preservation of local identities, the B2 scenario describes a world in which the emphasis is on local solutions to economic, social and environmental sustainability. It is a world with continuously increasing global at a rate lower than A2. The scenarios projected of summer maximum temperatures at Mexicali City, and annual maximum daily rainfall at Villahermosa City, were built for periods 2010-2039, 2040-2069 and 2070-2099, called of the 2020's, 2050's and 2080's, respectively.

\subsection{Scenarios of summer maximum temperature at Mexicali City}

Scenarios of summer maximum temperatures at Mexicali City are shown in the Table 6.

Table 6 shows: 1) Each month shows a steady increase in summer maximum temperatures, both with medium emissions scenario (B2) and with high emissions (A2). With the same emissions scenario (A2 or B2) September is the one with the largest increase, indicating that the summer could be increasingly longer and more intense; 2) For the 2020's the largest increase in summer maximum temperature is with B2 emissions scenario, compared to A2. With respect to the baseline scenario (1961-1990) July presented the largest increase $\left(2.5^{\circ} \mathrm{C}\right)$, followed by the months of September, August and June, with $2.4{ }^{\circ} \mathrm{C}, 1.4{ }^{\circ} \mathrm{C}$ and $1.3{ }^{\circ} \mathrm{C}$, respectively; 3) For the 2050's the largest increase in summer maximum temperature is with 
A2 emissions scenario, except the month of September. The largest increase would be in September with $4.2{ }^{\circ} \mathrm{C}$, followed by July, June and August, with $3.0^{\circ} \mathrm{C}, 2.6{ }^{\circ} \mathrm{C}$ and $2.1{ }^{\circ} \mathrm{C}$, respectively; and 4) For late XXI century, the largest increase in summer maximum temperature would have again with the A2 emissions scenario; the month of September would be the largest increase, up to $5.4^{\circ} \mathrm{C}$, followed by the months of July, August and June, with $4.1^{\circ} \mathrm{C}, 3.7^{\circ} \mathrm{C}$ and $3.5^{\circ} \mathrm{C}$, respectively.

\begin{tabular}{|c|c|c|c|c|c|c|c|}
\hline \multirow{4}{*}{ Month } & \multicolumn{7}{|c|}{ Summer Maximum Temperature $\left({ }^{\circ} \mathrm{C}\right)$} \\
\hline & \multirow{3}{*}{$\begin{array}{l}\text { Observed } \\
\text { Climate } \\
\text { Baseline } \\
(1961-1990)\end{array}$} & \multicolumn{6}{|c|}{ Future Scenarios } \\
\hline & & \multicolumn{2}{|c|}{$2020^{\prime} \mathrm{s}$} & \multicolumn{2}{|c|}{$2050^{\prime} \mathrm{s}$} & \multicolumn{2}{|c|}{$2080^{\prime} \mathrm{s}$} \\
\hline & & A2 & B2 & A2 & B2 & A2 & B2 \\
\hline June & 49.1 & 50.0 & 50.4 & 51.7 & 51.1 & 52.6 & 51.2 \\
\hline July & 48.1 & 50.0 & 50.6 & 51.1 & 50.7 & 52.2 & 51.3 \\
\hline August & 49.4 & 50.6 & 50.8 & 51.5 & 51.0 & 53.1 & 51.8 \\
\hline September & 47.0 & 49.3 & 49.4 & 50.5 & 51.2 & 52.4 & 50.9 \\
\hline
\end{tabular}

Table 6. Observed and Future Scenarios of summer maximum temperature for the 2020's, 2050's and 2080's at Mexicali City, Mexico with A2 and B2 emissions scenarios.

\subsection{Scenarios of maximum daily rainfall at Villahermosa City}

Figure 10 shows that neither with the high emissions scenario A2 would expect the maximum rainfall reaches $340 \mathrm{~mm}$, recorded in October in baseline scenario of 1961-1990.

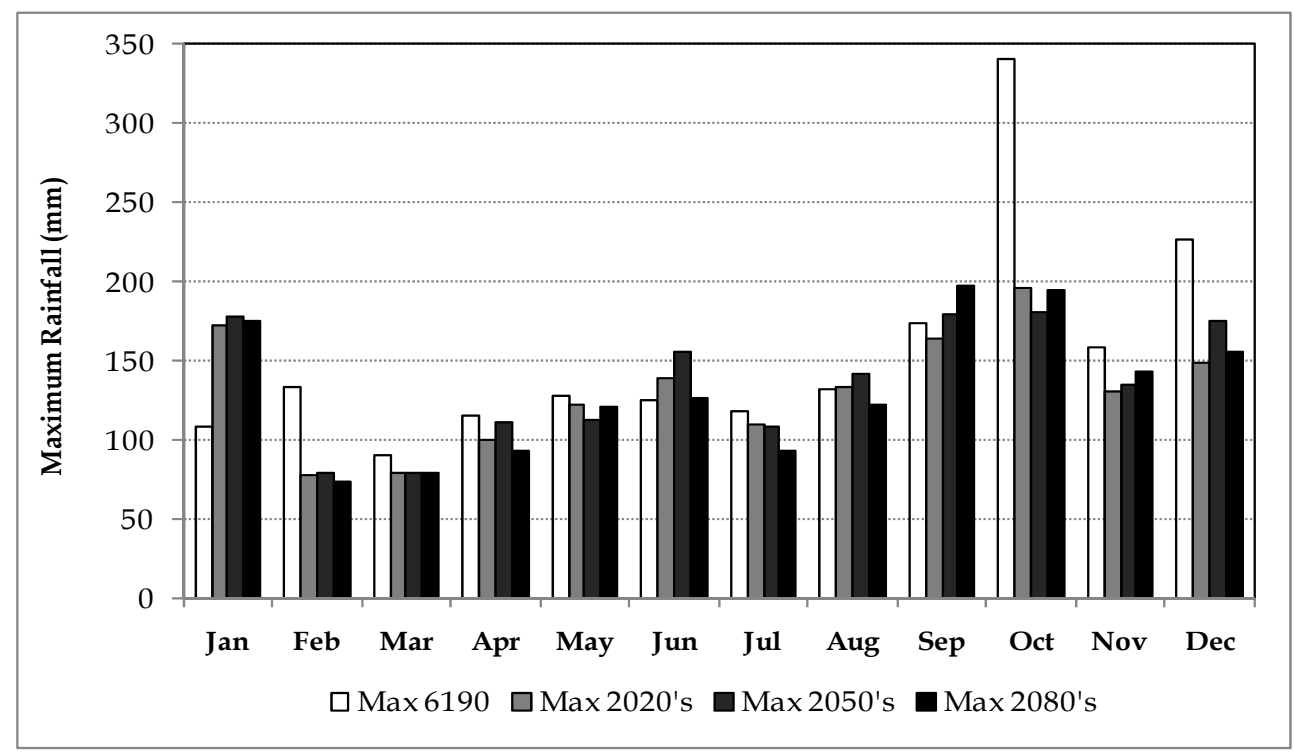

Fig. 10. Monthly daily maximum rainfall in a baseline scenario (1961-1990) and projected monthly maximum daily rainfall for the 2020's, 2050's and 2080's at Villahermosa City, with A2 emissions scenario. 
Taking into consideration a measure of variability such as standard deviation, by the end of XXI century is expected that the maximum rainfall for the month of October is in the range from $140.5 \mathrm{~mm}$ to $250.3 \mathrm{~mm}$. Also, by the end of the century in the month of January is expected a strong increase in the maximum rainfall, although the high variability determines an interval from $118.4 \mathrm{~mm}$ to $231.7 \mathrm{~mm}$; in the months of February and December, noted that in contrast to that recorded in the baseline scenario, the maximum rainfall in the future scenarios are below that value, even considering that the standard deviation for the months of February and December are $16.6 \mathrm{~mm}$ and $54.9 \mathrm{~mm}$, respectively.

\section{Discussion}

The results obtained in this chapter are based on the theory of extreme values that has a strong theoretical background and the realization of climate scenarios with a downscaling model, under A2 and B2 emissions scenarios. The basic premise relies on the assumption of asymptotic argument that converges to the three limiting distributions, as the size of the time series increases. Theoretically it is expected that for a time series infinitely large, the models correctly reproduce the tails of underlying distribution. In our case we have time series of limited size, so there always is an element of doubt when estimating the parameters of the chosen distribution, and when one is extrapolating values toward that, there is some uncertainty. However, EVT makes the best use of whatever data is available about extremes. In our case, the present results seem to support the fact that statistics of summer maximum temperature and daily maximum rainfall are well replicated under the background of extreme value theory. The fact that the theory explains the extreme events studied in this chapter supports the assertion of that EVT is able to estimate extreme quantiles for a short record of data.

In the case of modeling daily maximum rainfall in Villahermosa City, although the method applied is certainly very valuable, it has, however, some limitations: 1) the POT method was used without de-clustering techniques, and 2) the underlying distribution of analyzed stochastic variables should be stationary, but this condition is not always true in weather events. Therefore, it is clear that future studies will be needed to gain confidence regarding goodness of fit of proposed model (Smith, 2001). Accordingly: i) Excesses of rainfall over the chosen threshold must be studied in clusters, ii) The seasonal trend should be removed before applying POT technique, iii) The rainy and dry seasons should be studied separately, and iv) Other covariates, besides time should be included.

The model chosen for building scenarios of temperature and rainfall, the SDSM model, is conceptually simple and is based on the relationships between predictands and the large scale atmospheric forcing, that has been used in several studies (Hashmi et al., 2009; Chu et al, 2010). One of the main advantages of this model is that can be used to provide sitespecific information and is computationally inexpensive. The major theoretical weakness is that its assumption basic is not verifiable, i.e., that the statistical relationship developed for the present day climate also hold under the different forcing conditions of possible future climates (Wilby \& Harris, 2006). Although the model is not very good at projecting extreme values, the results found seem encouraging, especially in regard to the positive trend of summer temperatures at Mexicali City, as it is according to the results of General Circulation Models and Regional Circulation Models. With respect to scenarios of maximum daily rainfall at Villahermosa City does not show a definite trend in all months. Another feature 
of the projections is not exceeding historical amounts recorded in the months of October and December. Importantly, none of the currently available statistical downscaling techniques has been able to reproduce the rainfall with all characteristics very well, so it would be important to use another downscaling technique to compare the results obtained with SDSM model.

Respect to comparative analysis between return periods obtained with extreme value theory and climate scenarios obtained with SDSM model, with A2 and B2 emissions scenarios, we can observe that summer maximum temperatures at Mexicali City, with both methods yields similar values. Per example, by end of century, with application of extreme value theory, one would expect that summer maximum temperature at Mexicali City will exceed about $51.2^{\circ} \mathrm{C}$, with a $95 \%$ confidence interval, in ${ }^{\circ} \mathrm{C}$, of 50.4 to 53.1 . Too, by end of century, but using SDSM model, the summer maximum temperature projected, with A2 emissions scenario, is about $53.1^{\circ} \mathrm{C}$. Regarding the comparison of extreme rainfall events at Villahermosa City with both extreme value theory and downscaling model SDSM, it appears that the SDSM results are conservative with respect to the results obtained with extreme value theory. Per example, by 2050's, it is expected that return period of maximum rainfall is between $232.5 \mathrm{~mm}$ and 335.9, while the SDSM is between $132.2 \mathrm{~mm}$ and $230.0 \mathrm{~mm}$; by the end of the century it is expected that return period of maximum rainfall is between $256.7 \mathrm{~mm}$ and $385.1 \mathrm{~mm}$, while the SDSM is between $149.8 \mathrm{~mm}$ and $245.2 \mathrm{~mm}$.

\section{Conclusions}

1. Extreme Value Theory was successfully applied to two climatic datasets.

2. GEV distribution was fitted by using a block maxima approach to summer maximum temperatures, using daily data collected at the meteorological station of Mexicali, Mexico. The diagnostic plots and $\chi^{2}$ goodness-of-fit test confirm the adequacy of this distribution for the data analyzed.

3. The most adequate distribution for modeling the summer maximum temperature occurrence at Mexicali, Mexico was the Weibull distribution. The estimation of the upper limit was $56.012^{\circ} \mathrm{C}$.

4. Return level confidence limits showed that the summer maximum temperature in Mexicali City was expect to exceed about $49.3^{\circ} \mathrm{C}$ on average every 10 years, about $50.7^{\circ} \mathrm{C}$ on average every 50 years, and about $51.2^{\circ} \mathrm{C}$ on average every 100 years. The $95 \%$ confidence intervals, in ${ }^{\circ} \mathrm{C}$, were $(48.7,50.0),(50.0,52.2)$, and $(50.4,53.1)$, respectively.

5. GPD model was fitted by using a peak over threshold approach for daily maximum rainfall, using daily data collected at the meteorological station at Villahermosa, Mexico. A threshold of $60 \mathrm{~mm}$ was chosen after a range of thresholds was demontrated. The evaluation of significance of the proposed model by likelihood ratio test was significant at the 95\% confidence level. The diagnostic plots and quantile graphs suggest that the underlying assumption for the GPD is reasonable for the data analyzed.

6. Return levels confidence limits showed that daily maximum rainfall at Villahermosa City, with a threshold of $60 \mathrm{~mm}$, was expect to exceed about $201.8 \mathrm{~mm}$ on average every 10 years, about $281.4 \mathrm{~mm}$ on average every 50 years, and about $320.9 \mathrm{~mm}$ on average every 100 years. The $95 \%$ confidence intervals, in $\mathrm{mm}$, were $(179.5,236.6),(232.5,335.9)$, and $(256.7,385.1)$, respectively. 
7. There are shortcomings in the POT method proposed for modeling daily maximum rainfall including not using de-clustering techniques and not removing seasonal trend.

8. Scenarios for summer maximum temperature and maximum rainfall, with SDSM model, and emission scenarios A2 and B2, for the 2020's, 2050's and 2080's, were generated.

9. The comparison between the results obtained by extreme value theory (return periods) and those obtained by downscaling technique shows that for summer maximum temperatures at Mexicali City, are similar throughout this century. For extreme rainfall events SDSM model presents conservative results, i.e. lower than those found with respect to GPD model.

10. It would be important to use another downscaling technique, for estimate extreme events of rainfall at Villahermosa City, to compare the results obtained with SDSM model.

11. Estimating future return levels, and elaborate scenarios, in both temperature and rainfall extremes, at Mexicali City and Villahermosa City, respectively, provides essential input to urban adaptation and planning strategies through the establishment of, for example, heat watch-warning systems or flood prevention strategies. It is obvious that modeling work presented here reflects some uncertainties, as do all models of natural processes. However, inaction to protect lives and property may cost more if we dare not act because of unresolved questions.

\section{References}

Asensio, A. (2007). Extreme value theory and the solar cycle. Astronomy and Astrophysics, Vol. 472, No. 1, pp. 293-298, ISSN 0004-6361

Beirlant, J.; Goegebeur, Y.; Segers, J. \& Tegels, J. (2004). Statistics of extremes: theory and applications, ISBN 0-471-97647-4, England

Berning, L. (2010). Improved estimation procedures for a positive extreme value index. Thesis $P h D$, Stellenbosch University, $259 \mathrm{pp}$.

Coles, S. (2001). An Introduction to Statistical Modeling of Extreme Values, ISBN 1-85233-459-2, London, Great Britain

Chu, J.; Xia, J.; Xu, C. \& Singh, V. (2010). Statistical downscaling of daily mean temperature, pan evaporation and precipitation for climate change scenarios in Haihe, China. Theoretical and Applied Climatology, Vol. 99, pp. 149-161, ISSN 0177-798X

Deguenon, J. \& Barbulescu, A. (2011). Study of Extreme Rainfall using GPD Model. International Journal of Mathematics and Computation, Vol. 11, No. 11, pp. 28-37, ISSN 0974-5718

De Haan, L. \& Ferreira, A. (2006). Extreme Value Theory: An Introduction. ISBN 9780387239460, New York

Dixon, P.; Ellison, A. \& Gotelli, N. (2005). Improving the precision of estimates of the frequency of rare events. Ecology, Vol. 86, No. 5, pp. 1114-1123, ISSN 0012-9658

Easterling, R. (2000). Climate extremes: Observations, Modeling and Impacts. Science, Vol. 289, No. 5847, pp. 2068-2074, ISSN 0036-8075

Easterling, D.; Evans, J.; Groissman, P.; Karl, R.; Kunkel, E. \& Ambenje, P. (2000). Observed variability and trends in extreme climate events: a brief review. Bulletin of the American Meteorological Society, Vol. 81, No. 3, pp. 417-425, ISSN 0003-0007 
Embrechts, P., Klüppelberg, C. \& Mikosch, T. 1997. Modelling extremal events for insurance and finance. Berlin: Springer

Finkenstädt, B. \& Rootzén, H. 2004. Extreme values in finance, telecommunications and the environment. ISBN 1-58488-411-8

Fisher, R.A. \& Tippett, L.H.C. 1928. On the estimation of the frequency distributions of the largest or smallest member of a sample. Proceedings of the Cambridge Philosophical Society, vol.24, pp.180-190

García-Cueto, R.; Tejeda-Martinez, A. \& Jauregui, E. (2010). Heat waves and heat days in an arid city in the northwest of Mexico: current trends and in climate change scenarios. Journal International of Biometeorology, Vol. 54, No. 4, pp. 335-345

Gilleland, E. \& Katz, R. (eds) (2005). Tutorial for the extremes toolkit: weather and climate applications of extreme value statistics, http://www.assessement.ucar.edu/toolkit

Gilleland, E. \& Katz, R. (2006). Analyzing seasonal to interannual extreme weather and climate variability with the extremes toolkit (extRemes), 18th Conference on Climate Variability and Change, 86th American Meteorological Society (AMS) Annual Meeting, 29 January - 2 February, 2006, Atlanta, Georgia.

Gnedenko, B. (1943). Sur la distribution limite du terme maximum d'une série aléatoire. Annals of Mathematics, vol.44, no.3, pp. 423-453

Gumbel, E. (1958). Statistics of Extremes, New York, ISBN 0-486-43604-7

Hadživuković, S. \& Emilija, N. (2005). R. A. Fisher and Modern Statistics. International Statistical Institute, 55th Session.

Hashmi, M.; Shamseldin, A. \& Melville, B. (2009). Statistical downscaling of precipitation: state-of-the-art and application of Bayesian multi-model approach for uncertainty assessment. Hydrology and Earth Systems Science, Vol. 6, pp. 6535-6579.

IPCC (2007). Climate Change 2007: The Physical Science Basis. Contribution of Working Group I to the Fourth Assessment Report of the Intergovernmental Panel on Climate Change [Solomon S., D. Qin, M. Manning, Z. Chen, M. Marquis, K.B. Averyt, M. Tignor \& H.L. Miller (eds.)]. Cambridge University Press, UK and NY, USA, 996 pp.

Jentsch, A.; Kreyling, J. \& Beieirkuhnlein, C. (2007). A new generation of climate-change experiments: events, not trends. Frontiers in Ecology and the Environment, Vol. 5, No. 7, pp. 365-374, ISSN 1540-9295

Katz, R. \& Brown, B. (1992). Extreme Events in a Changing Climate: Variability is More Important than Averages. Climatic Change, Vol. 21, No. 3, pp. 289-302, ISSN 01650009

Katz, R.; Brush, G. \& Parlange, M. (2005). Statistics of extremes: modeling ecological disturbances. Ecology, Vol. 86, No. 5, pp. 1124-1134, ISSN 0012-9658

Katz, R.; Parlange, M, \& Naveau, P. (2002). Statistics of extremes in hydrology. Advances in Water Resources Vol. 25, No. x, pp. 1287-1304, ISSN 0309-1708

Kharin, V. \& Zwiers, F. (2005). Estimating extremes in transient climate change simulations, Journal of Climate 18, pp. 1156-1173

Kharin, V.; Zwiers, F.; Zhang, J. \& Hegerl, G. (2007). Changes in temperature and precipitation extremes in the IPCC ensemble of global coupled model simulations. Journal of Climate, Vol. 20, No. x, pp. 1419-1444, ISSN 0894-8755

Kotz, S. \& Nadarajah, S. (2000). Extreme Value Distributions: Theory and Applications. ISBN 978-1860942242 London 
Leadbetter, M.; Lindgren, G. \& Rootzén H. (1983). Extremes and related properties of stationary sequences and processes. ISBN 0387907319 New York

Meehl,G;, Zwiers, F.; Evans, J.; Knutson, T.; Mearns, L. \& Whetton, P. (2000). Trends in extreme weather and climate events: issues related to modeling extremes in projections of future climate change. Bulletin of the American Meteorological Society, Vol. 81, No. 3, pp. 427-436, ISSN 0003-0007

Navarra, A. (1999). The Development of Climate Research, In Analysis of Climate Variability, H. von Storch \& A. Navarra (Eds), 3-10, Springer, ISBN 3-540-66315-0, Heidelberg, Alemania

Naveau, P.; Nogaj, M.; Amman, C.; Yiou, P.; Cooley, D. \& Jomelli, V. (2005). Statistical methods for the analysis of climate extremes. Comptes Rendus Geoscience, Vol. 337, No. x, pp. 1013-1022, ISSN 1631-0713

Palmer, T. \& Räisänen J. (2002). Quantifying the risk of extreme seasonal precipitation events in a changing climate. Nature, No. 415, pp. 512-514, ISSN 0028-0836

Parmesan, C.; Root, T. \& Willig, M. (2000). Impacts of extreme weather and climate on terrestrial biota. Bulletin of the American Meteorological Society, Vol. 81, No. 3, pp. 443-450, ISSN 0003-0007

Pickands, J. (1975). Statistical inference using extreme order statistics. Annals of Statistics, vol.3, pp. 119-131

Pielke, R. (2007). Extremes in global climate models. Proceedings Winter Workshop Extreme Events, pp. 131-140, Hawai, USA, January 23-26, 2010

R Development Core Team, (2010). A language and environment for statistical computing. $\mathrm{R}$ Foundation for Statistical Computing, ISBN 3-900051-07-0, http://www.R-project.orgç

Reiss, R. \& Thomas, M. (2007). Statistical analysis of extreme values: with Applications to Insurance, Finance, Hydrology and Other Fields, ISBN 978-3764372309, New York

Rusticucci, M. \& Barrucand, M. (2004). Observed trends and changes in temperature extremes over Argentina. Journal of Climate, Vol. 17, No. X, pp. 4099-4107, ISSN 0894-8755

Smith, R. (2001). Environmental Statistics, Department of Statistics, University of North Carolina, USA pp. 377, Available from http://www.stat.unc.edu/postscript/rs/envnotes.ps

Tebaldi, C.; Hayhoe, K; Arblaster, J. \& Meehl, G. (2006). Going to the extremes. Climatic Change, Vol. 79, pp. 185-211, ISSN 0165-0009

Wilby, R.; Dawson, C. \& Barrow, E. (2002). SDSM- a decision support tool for the assessment of regional climate change impacts. Environmental Modeling Software, Vol. 17, pp. 145-157.

Wilby, R. \& Harris, I. (2006). A framework for assessing uncertainties in climate change impacts: low flow scenarios for the River Thames, UK. Water Resources Research, Vol. 42, W02419, doi10.1029/2005WR004065

WMO, (2011). Weather extremes in a changing climate, ISBN 978-92-63-11075-6, Geneva

Yin, J. \& Branstator, G. (2007). Extremes in global climate models. Proceedings Winter Workshop Extreme Events, pp. 67-72, Hawai, USA January 23-26, 2010. 


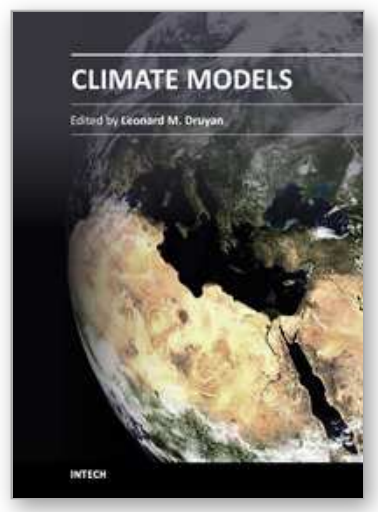

\author{
Climate Models \\ Edited by Dr. Leonard Druyan
}

ISBN 978-953-51-0135-2

Hard cover, 336 pages

Publisher InTech

Published online 02, March, 2012

Published in print edition March, 2012

Climate Models offers a sampling of cutting edge research contributed by an international roster of scientists. The studies strive to improve our understanding of the physical environment for life on this planet. Each of the 14 essays presents a description of recent advances in methodologies for computer-based simulation of environmental variability. Subjects range from planetary-scale phenomena to regional ecology, from impacts of air pollution to the factors influencing floods and heat waves. The discerning reader will be rewarded with new insights concerning modern techniques for the investigation of the natural world.

\title{
How to reference
}

In order to correctly reference this scholarly work, feel free to copy and paste the following:

O. Rafael García-Cueto and Néstor Santillán-Soto (2012). Modeling Extreme Climate Events: Two Case Studies in Mexico, Climate Models, Dr. Leonard Druyan (Ed.), ISBN: 978-953-51-0135-2, InTech, Available from: http://www.intechopen.com/books/climate-models/modeling-extreme-climate-events-two-case-studies-inmexico

\section{INTECH}

open science | open minds

\section{InTech Europe}

University Campus STeP Ri

Slavka Krautzeka 83/A

51000 Rijeka, Croatia

Phone: +385 (51) 770447

Fax: +385 (51) 686166

www.intechopen.com

\section{InTech China}

Unit 405, Office Block, Hotel Equatorial Shanghai

No.65, Yan An Road (West), Shanghai, 200040, China

中国上海市延安西路 65 号上海国际贵都大饭店办公楼 405 单元

Phone: +86-21-62489820

Fax: +86-21-62489821 
(C) 2012 The Author(s). Licensee IntechOpen. This is an open access article distributed under the terms of the Creative Commons Attribution 3.0 License, which permits unrestricted use, distribution, and reproduction in any medium, provided the original work is properly cited. 